\title{
Uterine arterio-venous malformation
}

\author{
Maxence Dorez • Jérôme Delotte • Sébastien Novellas • \\ Patrick Chevallier • André Bongain
}

Received: 11 May 2010 /Accepted: 1 July 2010 /Published online: 21 August 2010

(C) Springer-Verlag London Ltd 2010

A 26-year-old patient presented at the emergency department because of uterine bleeding for the previous 3 days. She had undergone voluntary termination of pregnancy by curettage 2 months before. Upon clinical examination, metrorrhagia was moderate, with heart rate: $90 / \mathrm{min}$, blood pressure: $110 / 80 \mathrm{mmHg}$ and temperature: $36.9^{\circ} \mathrm{C}$.

Intra-vaginal ultrasound examination showed a heterogeneous intra-uterine $30 \times 20 \mathrm{~mm}$ image suggesting the presence of ovulatory debris following curettage, but the significant vascular supply of this mass upon colour Doppler imaging, revealing a high velocity vascular network, was in favour of an uterine arterio-venous malformation (AVM) [1, 2]. The diagnosis was confirmed upon arterial computed tomography showing the UAVM was located in the portion joining the uterine body and fundus and mainly supplied by the left uterine artery.

Treatment consisted in selective embolization of the UAVM [3, 4]. There were no complications or any further bleeding (Figs. 1, 2 and 3).

Metrorrhagia is a frequent motive of presentation at the emergency department and often leads to curettage as uterine retention is the common diagnosis. Performing colour Doppler imaging in such a context may reveal the presence of an AVUM, a situation in which curettage could lead to massive and potentially fatal haemorrhage through direct vascular trauma [5].

M. Dorez $(\bowtie) \cdot$ J. Delotte $\cdot$ A. Bongain

Obstetrics and Gynecology Unit Archet II,

University Hospital of Nice,

Route St Antoine de Ginestière,

06202 Nice Cedex 3, France

e-mail: medmaxence@hotmail.com

S. Novellas $\cdot$ P. Chevallier

Imaging Unit Archet II, University Hospital of Nice,

Route St Antoine de Ginestière,

06202 Nice Cedex 3, France

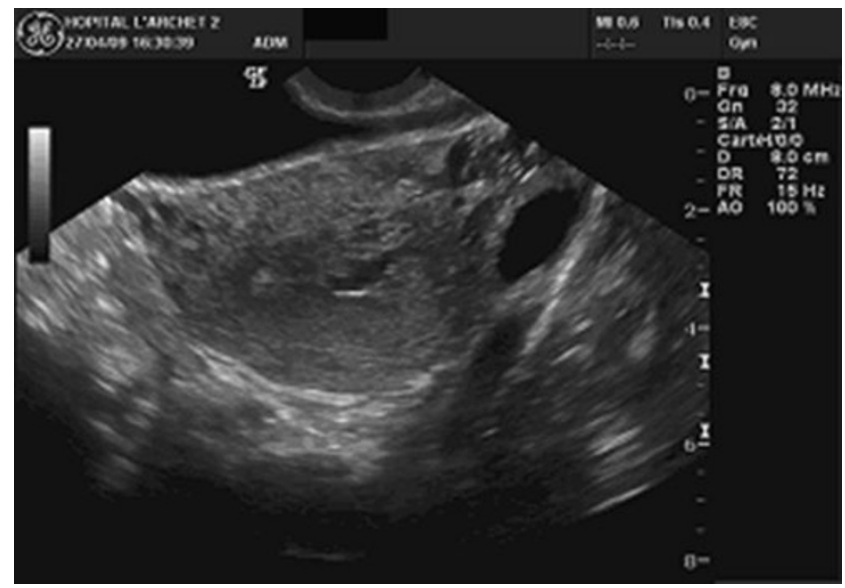

Fig. 1 Ultrasonography: heterogeneous intra-uterine image

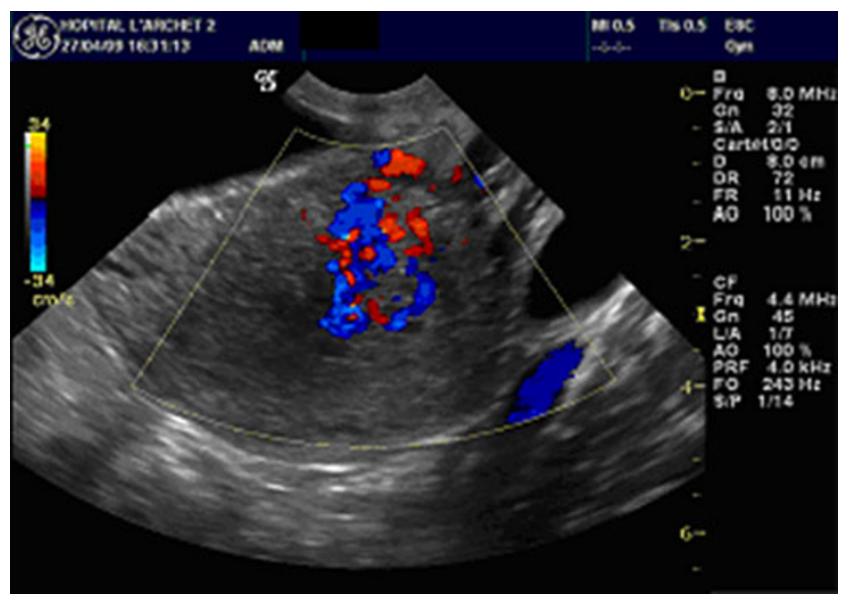

Fig. 2 Colour Doppler ultrasonography: hypervascularisation 


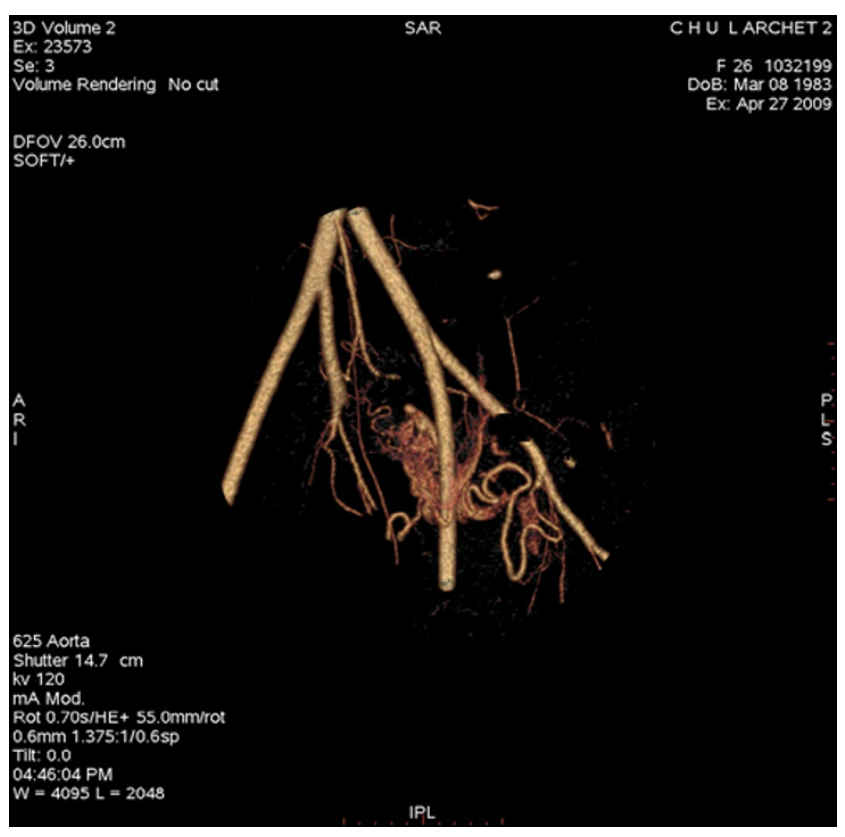

Fig. 3 Arterial CT scan: left uterine arterio-venous malformation
Conflict of interest None

\section{References}

1. Polat P, Suma S, Kantarcy M, Alper F, Levent A (2002) Color Doppler US in the evaluation of uterine vascular abnormalities. Radiographics 22:47-53

2. Timmerman D, Van den Bosch T, Perraer K, Debrouwere E, Van Schoubroeck D, Spitz B (2000) Vascular malformations in the uterus: ultrasonographic diagnosis and conservative management. Eur J Obstet Gynecol Reprod Biol 92:171-178

3. Grivell RM, Reid KM, Mellor A (2005) Uterine arteriovenous malformations: A review of the current literature. Obstet Gynecol Surv 60(11):761-767

4. Timmerman D, Waters J, Van Calenbergh S, Van Schoubroeck D, Maleux G, Van den Bosch T et al (2003) Color Doppler imaging is a valuable tool for the diagnosis and management of uterus vascular malformations. Ultrasound Obstet Gynecol 21:570-577

5. Halperin R, Schneider D, Maymom R, Peer A, Pansky M, Herman A (2007) Arteriovenous malformation after uterine curettage: a report of three cases. J Reprod Med 52(5):445-449 